\title{
Quem são Eles?
}

\author{
Francisco Martins ${ }^{1}$ e Arílson Corrêa da Costa \\ Universidade de Brasília
}

\begin{abstract}
RESUMO - O texto apresenta análises e reflexões desenvolvidas no Laboratório de Psicopatologia e Psicanálise da Universidade de Brasília acerca da questão do(s) ‘ele(s)' na obra O Processo, de Franz Kafka, e em um caso de delírio de perseguição. Investigou-se especialmente o estatuto do pronome 'ele' na paranóia. O trabalho mostra que o entendimento do que "é (são) ele(s)" é elemento essencial para a elucidação da questão da estranheza na psicose e da construção da atividade delirante. O estudo da dimensão referencial da linguagem se revela então particularmente importante. Ao longo do texto são apontadas algumas questões e articulações entre a análise procedida, a psicanálise, a fenomenologia e a comunicação lingüística, tendo como hipótese essencial que a psicose consiste na perda e reconstrução narcísica da função referencial da linguagem.
\end{abstract}

Palavras-chave: psicose; referência; delírio.

\section{Who are They?}

\begin{abstract}
The text presents analysis and reflections developed at the Psychopathology and Psychoanalysis Laboratory of the University of Brasilia on the issue of the "he (they)" in Franz Kafka's work The Process and on a case of persecution delusion. The particular status of pronoun "he" in paranoia is investigated. The paper shows that the understanding of what "he (they) is (are)" is an essential element for elucidating the experience of the strangeness in psychosis and the construction of the delusional activity. The study of the referential dimension of language then proves to be of paramount importance. Along the text one points out some issues and articulations between the analysis carried out, psychoanalysis, phenomenology and linguistic communication, having as the essential hypothesis the assumption that psychosis consists on the loss and narcissistic reconstruction of the referential function of language.
\end{abstract}

Key words: psychosis; reference; delusion.

'Objets inanimés, avez-vous donc une âme?' Lamartine

Aprendemos com Freud (1919/1976) que a inquietante estranheza (Das Unheimlich) é um fenômeno que não pertence somente às variações anormais da vida psíquica. Ela está potencialmente presente na vida cotidiana de todos nós. Está potencializada em toda psicanálise uma vez que estamos sempre, neste último caso, em terreno estranho, esquisito, inusitado, desconhecido daquilo que nos é familiar. Ela ocorre sempre com algo que é exterioridade e estrangeiro enquanto experiência consciente. Freud mostrou que a inquietante estranheza traz consigo conteúdos de ordem do familiar que são, porém, relegadas ao inconsciente. Temos trabalhado no Laboratório de Psicopatologia e Psicanálise na perspectiva de que aquilo que é anormal, patológico, alienado, estrangeiro, pode nos ensinar acerca do vir a ser humano. Foi a partir desta perspectiva pathoanalítica, lembrando o neologismo schottiano (1982), que iniciamos o estudo de uma das obras de Kafka (1926/1957): O processo. Essa obra tem o caráter de universalidade, não exigindo, por isso mesmo, nenhum elogio ou afirmação de reputação. Ela afirma e nos introduz neste estranho e estranhado mundo da paranóia não mais como um mundo somente de loucos e paranóicos, mas como uma possibilidade de todos nós.

1 Endereço: Universiddae de Brasília, Instituto de Psicologia, Campus Universitário Asa Norte, Brasília, DF 70910-900.

\section{O Sr. K. e ele(s)}

Na leitura de $O$ Processo não temos tempo para uma reflexão que crie uma atividade representativa e que nos coloque na exterioridade da vida de Joseph K. Somos surpreendidos ou, melhor ainda, jogados repentinamente em um mundo estranho, de chofre, sem nenhum preparo. O Sr. K., ao acordar, tem a nítida impressão, uma certeza que se estabelece passo a passo, de que está sendo caluniado por alguém. A calúnia, rápido, muito rápido mesmo, começa a se efetivar como uma perseguição com ares de legalidade. A visita surpresa sofrida por Joseph K. desencadeia uma experiência de terror. A vivência construída a partir do susto,, do despreparo e da intrusão violenta coloca Joseph K. frente a uma instância desconhecida. Mais além da calúnia, da violência, da experiência da agressão gratuita, é terrificante que não seja dada precisão a esse alguém, a esse "ele" incógnito.

"Eles" não pronunciam a acusação. A sua indeterminação e a falta de referenciais são os elementos utilizados na narrativa de Kafka para criar a atmosfera paranóica. Esse 'ele' que permanece igualmente indeterminado no singular, podendo ser o sistema, a empresa, o estado, qualquer pessoa, um amigo, um inimigo, é profundamente ameaçador. As perguntas que Joseph K. se formula frente ao grupo de desconhecidos que o interpela são significativas na busca de se referenciar neste estranho e estranhado mundo: o que é isto?, onde estou?, em que momento fiz algo errado? Conjuntamente com outras perguntas, tais como "quem sou eu?", "será que eu sou culpado?”, Joseph K. concentra sua angústia na busca desse 
'ele' indeterminado, impessoal, face à instância desconhecida na interrogativa fundamental: quem são eles?

Definitivamente o mundo está inseguro, afastado do aconchego dos que podem amá-lo. Definitivamente passa a ocorrer uma preocupação extremada com 'ele', com uma concomitante degradação da situação de interlocução: todos podem vir a ser 'ele(s)', desaparecendo o alocutor. Emerge um discurso onde o 'tu', o sujeito a quem se dirige a palavra é virtualmente um 'ele', ocorrendo por isso mesmo a demolição deste alocutor, crescendo o 'eu' e o 'ele'.

Emerge no livro de Kafka uma proximidade com o discurso tipicamente paranóico, na medida em que ficam pairando sobre o 'eu' possibilidades infinitas de afetação e ataques. Contudo, no discurso do Sr. K., mesmo sofrendo a perseguição, inquéritos, apresentações em um júri, enfim, um processo, não podemos dizer que o Sr. K. estaria pura e simplesmente sofrendo de um delírio de perseguição. Ele é um delirante em potencial. O gênio literário de Kafka mantém em suspenso até o final da obra, o objeto do processo, os nomes dos perseguidores, os motivos; enfim, nada sabemos sobre essa dimensão terceira, objeto do discurso do Sr. K.

Nas falas de nossos pacientes paranóicos encontramos essa mesma demolição do processo de interlocução. Eles falam muito de si e do objeto do seu discurso, via de regra 'ele' pessoa, coisa, objeto. O 'tu' tende a desaparecer, na medida que nem sempre é considerado como digno de interlocução. Conhecemos de longa data a querelância na paranóia e os riscos deste 'tu' ser tomado como um adversário. Diferentemente do Sr. K., os paranóicos conseguem dar precisões acerca de quem são "eles" e até constroem um saber acerca de uma série de objetos. Em outras palavras, eles constroem todo um mundo novo.

Nossa interrogação acerca desse 'ele' indeterminado leva-nos necessariamente a estudar a chamada função de referenciação da linguagem. Isto é, a possibilidade que tem a linguagem de nos enviar ao mundo extra-lingüístico, seja ele real, efetivo, material, ou imaginário, possível. Este mundo extra-lingüístico é mediado na interlocução principalmente pela referência a essa terceira pessoa, objeto, assunto, tema, coisa, via de regra excluída da interlocução 'eu' - 'tu'. Nunca é demasiado antes de prosseguirmos nosso estudo dar maiores precisões acerca da referência e dos pronomes em ação na interlocução.

\section{O que é 'ele' na linguagem: a questão da referência.}

O conceito de referência foi definido classicamente por Frege (1892/1978), que afirmou ser o referente de uma expressão o objeto que ela designa. A concepção fregeana enfatiza assim a distinção existente entre sentido e referência. O referente de uma expressão diz respeito ao objeto referido. Já o sentido de uma expressão quer dizer, segundo Ducrot e Todorov (1972), a maneira específica pela qual ela conceitua um objeto determinado. Frege atém-se essencialmente à realização de análises de enunciados, de proposições, sobre se elas são verdadeiras ou falsas. Foi com o advento dos chamados filósofos da linguagem ordinária, em especial Austin (1962/1990), que um aprofundamento acerca das relações entre a interlocução e os efeitos pragmáticos desta, mostrou a importância da referência para mais além da análise fregeana. Assim, em nosso estudo, tratamos de mostrar não somente se a fala é delirante ou não, mas, principalmente, em verificar como o mundo se constituiu para aquele sujeito. Ou seja, pela análise dos diversos componentes constituidores da referência, temos acesso não mais somente às coisas que aparecem para o sujeito, mas aos objetos que emergem, nascem, se realizam e se concretizam face ao mesmo e, por conseqüência, ao mundo.

Uma análise inspirada em Frege nos enviaria a elaborações da chamada referência absoluta, isto é, interrogarmos sobre se cada lexema envia a um determinado objeto existente na realidade efetiva concreta. Caso nos interessemos pela realização não mais somente absoluta da referência mas também de uma referência relativa à situação específica da enunciação, somos enviados à articulação da linguagem a pelo menos duas outras dimensões. Uma primeira, que chamaremos de referência relativa ao co-texto (endofórica), e uma segunda relativa ao contexto (exofórica), ou seja, relativa não mais ao meio ambiente, mas ao próprio discurso. O quadro 1 procura evidenciar a análise geral da referência mostrando os envolvimentos principais quanto a algumas dimensões da linguagem.

Quadro 1. Os tipos de referência e os seus elementos lingüísticos.

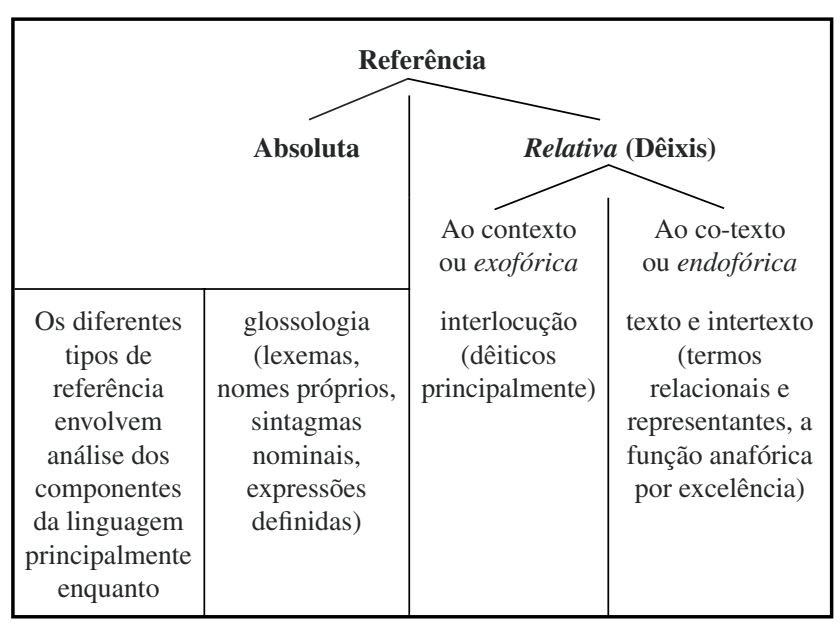

Considerando a questão específica trazida pelo mundo do Sr. K., bem como a importância da questão do 'ele', nos ateremos especificamente à referência do tipo exofórica, aquela constituída pela chamada dêixis discursiva. A dêixis envolve necessariamente três componentes: a pessoa, o tempo e o espaço. A definição do termo dêixis remete ao domínio da subjetividade do enunciado, evidenciando, assim, a origem subjetiva do processo de referenciação e o fato de que, no caso das expressões referenciais dêiticas, o contexto do enunciado não é apenas externo, extensional ou ontológico. Pelo contrário, o contexto dêitico focaliza o aqui e agora do locutor, a situação específica do ato de enunciação. Tal sistema de dêixis, baseado no falante, é chamado "sistema egocêntrico", noção elaborada a partir da concepção de Russell. B. (1966) de que os particulares egocêntricos (aqui, agora, eu, isto) são palavras cuja denotação é relativa ao locutor. A relação estabelecida entre dêixis e referência remete ao fato de que a referência não é fixa para alguns vocábulos, isto porque as coordenadas espaço-temporais e de pessoa são sempre 
relativas e mudam em função da perspectiva que se toma. $\mathrm{O}$ objeto denotado pelas expressões referenciais relativas se define como dado dentro do contexto relacional do ato comunicativo. Cada vez que a situação de enunciação se modifica, a referência se verá igualmente modificada. Porém, a mudança da situação da enunciação não altera o significado dêitico que é constante e reside na indicação das relações com o contexto específico do ato discursivo. A referência é fixada pela série de índices particulares denominados dêiticos, expressões cujo referente só pode ser determinado em relação aos interlocutores e dentro do contexto da enunciação. A referência é vista como estando em dependência da situação de enunciação e tanto a semântica lógica quanto a semântica lingüística coincidem em afirmar que "sendo o domínio (range) referencial das expressões referenciais fixado pelo sentido que têm na língua, sua referência efetiva depende da variedade dos fatores contextuais" (Parret.H., 1988). Esta observação pontual mostra que a dêixis constitui uma espécie de triângulo com seus componentes diversos que procuramos explicitar no quadro 2.

O pronome de terceira pessoa está situado, dentro do triângulo dêitico proposto por Herman Parret, no campo do não-eu e consequentemente, em oposição ao campo do eu, paradigma do demonstrativo indicial puro. O pronome "eu" indica o locus da enunciação. A partir da organização egocêntrica proposta por este autor, criador de uma teoria da dêixis em que todo o domínio das categorias dêiticas se organiza ao redor do Eu e a qual denominou "teoria egocêntrica da dêixis", é necessário estabelecer uma distinção entre duas modalidades: dêiticos puros e impuros. Os primeiros, eu e tu, aqui e agora, fazem referência aos participantes da interlocução, sem transmitir informações adicionais. Por outro lado, os dêiticos impuros, cujo paradigma é o pronome pessoal "ele", estabelecem diferenciações baseadas em características e propriedades do referente que são independentes das coordenadas espaciais e temporais em que se encontram o locutor e o receptor de um determinado discurso.

Na concepção de Benveniste (1966), a classe dos pronomes denominados de "terceira pessoa", cujo paradigma é o "ele", é uma categoria perfeitamente diferenciada dos pronomes "eu" e "tu", tanto pela sua função como pela sua natureza. No que diz respeito à função dos pronomes de terceira pessoa, eles substituem um segmento do enunciado ou a totalidade de um enunciado, constituindo-se em substitutos abreviativos. Desta maneira, o pronome "ele", ao qual Benveniste denomina "não-pessoa", representa o membro não marcado da correlação de pessoa, cujos paradigmas são "eu" e "tu". A partir desta definição, o autor afirma que a referência de não-pessoa é uma "referência zero", que permanece fora da relação "eu"/"tu".

O que caracteriza os pronomes da terceira pessoa, seus traços distintivos, são as seguintes propriedades: a) sua capacidade de se combinar com qualquer referência de objeto; b) o fato de não ser reflexiva da instância do discurso; c) a possibilidade de envolver um grande número de formas pronominais e demonstrativas; d) a sua incompatibilidade com termos referenciais tais como "aqui" e "agora", que são expressões dêiticas paradigmáticas, uma vez que expressam as coordenadas determinadas pelo locus tempo-espacial da enunciação.

A comunicação impersonalizada necessariamente privilegiará as posições relacionadas aos termos "ele", "depois", "ali", registrando-se um aumento na distância entre o Eu (locutor) e o possível tu (alocutor), terminando por fazer desaparecer esse tu e tratando todos como um ele, um objeto exterior à interlocução. Assim, o discurso paranóico acerca do "ele(s)" mantém a distância, realiza a máxima de não entrar em contacto, do não personalizar. Quando isto ocorre, quando o "tu" é hiperinvestido, o comportamento acaba por se transformar em querelância, ou eventualmente litígio, e corre-se o risco de se ser tomado como um "ele" perseguidor. Pensamos existir uma relação estreita entre a paranóia e esse mundo impessoal e frio introduzido pelo pronome "ele", sem possibilidade de diálogo. A constância da fala com relação a uma terceira pessoa leva-nos a interrogar acerca do estatuto específico deste chamado pronome pessoal. Efetivamente, Benveniste nos ensina que esse dêitico não é exatamente um pronome pessoal mas, muito mais, um pronome impessoal. Mesmo que não concordemos que "ele" não seja um pronome pessoal, temos que concordar que "ele" vai em direção ao impessoal e diz respeito ao não-familiar, ao indiferente, ao ausente, à não-pessoa, às coisas.

\section{A dêixis no Sr. K. e no delírio de perseguição}

Assinalamos na estória do Sr. K. o aparecimento de um mundo extremamente inseguro. Este clima de insegurança generalizada pode ser reencontrado nos três planos do triângulo dêitico do mesmo modo em que ocorrem as irrupções de conflitos e incertezas na realidade cotidiana do Sr. K. Efetivamente pensamos que é esta uma das pedras de toque do gênio de Kafka: conseguir manter um clima de indefinição, de terror, de apreensão possível e que vai se realizando ao longo do processo, sem especificação final dos referentes. Claro que diversos personagens e causas são indicadas ao longo da narrativa. No entanto, ao concluirmos a leitura, temos a sensação do absurdo acerca do mundo vivido pelo personagem de Kafka. Podemos até pensar: em um mundo onde nada toma definições, tudo se torna possível. Assim, com relação a "ele", a despeito do deslizamento de objetos, finalmente sentimo-nos inseguros com relação ao mundo efetivo que se forma: interroga-se acerca do indefinido que sempre é potencialmente perturbador.

Mas a indefinição desesperadora não se passa somente com relação ao impessoal. As pessoas, mesmo aquelas as mais próximas, tendem a se transformar em alguém indife-

Quadro 2. O triângulo dêitico.

\begin{tabular}{|c|c|c|c|c|c|c|c|c|c|c|c|}
\hline \multicolumn{4}{|c|}{ pessoa } & \multicolumn{4}{|c|}{ tempo } & \multicolumn{4}{|c|}{ espaço } \\
\hline \multirow[t]{2}{*}{ eu } & \multicolumn{3}{|c|}{ não-eu } & \multirow[t]{2}{*}{ agora } & \multicolumn{3}{|c|}{ não-agora } & \multirow[t]{2}{*}{ aqui } & \multicolumn{3}{|c|}{ não-aqui } \\
\hline & tu & ele & $\begin{array}{c}\text { a gente, } \\
\text { se }\end{array}$ & & antes & depois & $\begin{array}{c}\text { era uma } \\
\text { vez }\end{array}$ & & aí & ali, lá & alhures \\
\hline
\end{tabular}


rente. Ou seja, pensamos que o "Tu", onde se situa a essência do pólo interlocutivo, tende a colabar, na medida em que não existe uma devida qualificação do que o sujeito ("Eu") tem a dizer. Isto é, tudo o que o Sr. K. diz termina por não ser considerado, resultando na transformação dos possíveis "Tu" em pessoas não dignas de interlocução. Assim a tendência geral é o ataque ao "Tu", transformando-os em objetos de discurso, ou seja em um "eles", em não-pessoa. Uma dimensão essencial que se cria nestes estados próximos e similares à paranóia é a extrema solidão final do locutor. Solidão em que se fecham mais ainda pela impossibilidade de confiarem em seus interlocutores imediatos. A cada pessoa nova tudo retorna: será que esse "Tu" é bom ou mal? A indefinição é anterior logicamente a qualquer diferenciação.

Viver em um mundo deste tipo fatalmente faz-nos pensar que existe algo no "Eu" do sujeito que propicia a construção de tanta indefinição. Isto é, para emergir o mundo humano, mundo de objetos preenchidos de significação, é necessário a existência de um "Eu" que se constitui em concomitância. Não é surpreendente que o personagem de Kafka termine volta e meia por se interrogar sobre o absurdo de ser tratado como um "Eu" que não é ele-mesmo. Ou seja, a interpelação radical sobre o próprio princípio de identidade resulta na fórmula da loucura com relação ao pólo locutivo: ser tomado por um outro que o sujeito não é. Trata-se de uma interrogação no verbo existencial ser que se reflete diretamente no dêitico "Eu". A solução do Sr. K. é realizar uma espécie de luta, muito mais um espernear, contra a intrusão que experimenta como vindo do exterior. A muito custo vemos o Sr. K. sustentar que ele é ele-mesmo. Esta posição projetiva do Sr. K., que não aceita nenhuma predicação com relação a si mesmo, o coloca próximo da paranóia, com a diferença de que o "Eu", na paranóia, termina por crescer defensivamente.

Assim, nas três instâncias dêiticas temos um envio para uma indefinição angustiante. Kafka consegue manter-nos nesta posição angustiante juntamente com o Sr. K. Pensamos, por isso, existir um íntimo parentesco entre esta posição e os momentos anteriores à constituição de um delírio, a vivência de significação (Jaspers, 1913/1987). O Sr. K. permanece na insegurança. Já a paranóia mostra quase sempre alguém seguro de si mesmo, extremamente responsável diria Gagnepain (1988), e certo da perseguição, conseguindo até nomeá-los, como ocorre no delírio de perseguição.

Lembremos de um caso, entrevistado por um colega nosso, para pensarmos acerca dos dêiticos nas psicoses. Trata-se de uma entrevista em um Pronto-Socorro e comandada pela urgência do responder psiquiátrico. Poderá ser notada uma preocupação do nosso colega em definir "aquilo do que se trata", daí não existir quase nenhum silêncio. Restringiremos nossa observação à fala do paciente e às partes referentes ao seu delírio por motivo da extensão da entrevista. Ao ser perguntado sobre quando a perseguição se iniciou, o paciente começa a dar precisões sobre quem o persegue, relacionando a perseguição ao fatídico problema do pai.

Psiquiatra: Seu pai faleceu quando?

Paciente: É. Faleceu...é...há dez anos atrás. Foi janeiro de 85.

Psiquiatra: E desde então...

Paciente: A perseguição corre solta.

Psiquiatra: Mas perseguição por parte de quem?
Paciente: Por parte do irmão da minha mãe.

Psiquiatra: Do irmão da sua mãe?

Paciente: É. Eu sobrevivi, né? Graças a Deus!

Psiquiatra: $\mathrm{O}$ que é que ele tem feito?

Paciente: Tem feito é...muito...é...muitas maneiras!

Psiquiatra: Por exemplo?

Paciente: Me boicotando em tudo.

Psiquiatra: Mas o que ele fez?

Paciente: Vou fazer um negócio, ele boicota, manda prender, bater com o cinto. Não quer pagar? Certo! Quebra mesmo, faz. a maior zona, quebra mesmo...que isso...que aquilo lá!

Psiquiatra: Não diretamente.

Paciente: Não diretamente. Ele fala isso me ameaçando. Só ameaça.

Psiquiatra: Dá um exemplo concreto, bem objetivo, do que já te aconteceu.

Paciente: Aconteceu de eu estar no hospital, tomar injeção na veia... O coração veio até aqui! Quase morri! Faz dois dias.

Psiquiatra: Eu digo assim, do boicote dele.

Paciente: Então! Antes de viajar por aí, se eu parasse, ele parava. Ele parava por causa daqueles quarenta e três mil hectares, certo? O recurso para eu pegar em Maringá num avião particular. Só que não tem nada a ver com ele, com o meu trabalho, porque o doutor N.C.B., que foi quem chamou a gente lá no Mato Grosso, que é um outro irmão do meu pai...Meu pai, que é...que...eu continuo, eu continuo...no qual...e o doutor E., que é o advogado de Maringá, nosso, da família...que eu continuo pensando sério em montar umas investigações aqui em Brasília de quem eu sou, quem é...Eu, quando eu fui pego, para ter que parar, a primeira coisa que eu pensei em fazer aqui...tem sirenes! Me perguntaram aqui foi "de onde você vem?" Eu virei: não! Vamos montar um escritório, mas eu primeiro...e fizeram-me telefonar é...e eu acho que eu fiz de qual forma que doze caras me bateram.

Psiquiatra: Doze?

Paciente: Doze! Me jogaram no chão e depois me deram um chute, aí...Onde é que fica? Na Justiça Federal, do lado direito do Chinês. Bateu muito, bateu muito, bateu muito no chão!

Psiquiatra: Aonde se tem um banco?

Paciente: Não, do lado esquerdo. Aquilo é tudo via comercial, do lado direito.

Psiquiatra: Isso foi aqui em Brasília?

Paciente: Foi. Em Brasília. Logo que eu cheguei.

Psiquiatra: E a história do hotel, como é que aconteceu?

Paciente: Fora do hotel eles me deixavam num cárcere privado.

Psiquiatra: Cárcere privado?

Paciente: É, cárcere privativo! Onde eles não me deixavam comer nem beber. Eles não queriam me dar água, ou de beber, ou de comer.

Psiquiatra: Eles quem?

Paciente: Os pessoal do hotel, o proprietário e tudo.

Psiquiatra: Mas não é proprietário?

Paciente: Eles? Não sei. Porque nunca falava a verdade. Ele só falou que liga, liga, liga e não sei o que lá. Eu só percebi quando chegou aqui perto uma caminhonete F-10 e eles chegaram e eu...eu fiquei...daí, eu vi que faltava muito dinheiro né? Muito! Eu gostaria de ter pago porque...Pôxa!...Questão de honra, de dever. Vou morrer! Morrer eu não vou. Se eu morrer daqui eu vou pro céu. 
A despeito de o discurso ser permeado por muitas interrupções, imprecisões, algumas frases incompletas e por redundâncias (típica de toda fala espontânea), pode ser evidenciado que o Sr. P., nosso paciente delirante continua vivendo em um mundo inseguro. Chamamos de paranóia justamente uma construção que visa liquidar a situação terrificante de insegurança e horror via utilização do imaginário de um ponto de vista narcísico. O delírio é construído como solução a essa grande interrogante que é o indeterminado. Diferentemente do personagem de Kafka vemos um sujeito cheio de certezas e ocupando o lugar do perseguido. Isto é, com relação a "eles", ocorre a constituição de um mundo cheio de significações. Sabemos, há bastante tempo, que nos delírios primários, o mundo começa a significar, a indicar causas, e o sujeito a entrar em uma vivência de significação (Jaspers, 1913/1987)), fenômeno fundamental para eclosão das percepções delirantes.

A referência se opera efetivamente no delírio paranóico. Isso tanto é verdade que conseguimos reconstruir os fatos do mundo criado pelo delirante, acompanhá-lo em suas asserções. Diferentemente da esquizofrenia, em que existe um ataque à noção de significação, no delírio estamos cientes do que o sujeito experimenta e descreve e, por essa razão, a psiquiatria clássica nomeou uma série de tipos de delírios diferentes fundados nos diversos temas. Se o processo de referenciação opera no delírio de perseguição isso não quer dizer que estejamos de acordo com o referente produzido, seja ele real, concreto ou imaginário. Uma das características essenciais do delírio, em contraposição à produção não delirante, é a radical produção de referentes que não estamos de acordo sobre a sua existência real ou imaginária. Isto é, o delirante está em discordância acerca das coisas mesmas do mundo e das explicações que temos acerca delas. Ele cria um mundo novo a partir do seu ponto de vista e dos seus desejos sem maiores considerações acerca do que os outros estão pensando. O delirante reconstrói, diria Freud (1976/1911).

Sendo o delírio um discurso acerca da realidade torna-se gritante a importância da categoria dêitica "eles". Assim, entendemos perfeitamente que o tio de P. é o perseguidor, o assassino do seu pai, o usurpador dos bens da família. No entanto, de fato, nada disso ocorreu. Diríamos que aquilo que é pura possibilidade lógica é tomada como realidade e verdade pelo paranóico. Emerge assim, em toda interlocução com um delirante, a possibilidade de se instalar a discordância acercada realidade.

Instala-se principalmente uma oposição Eu - Ele. O "Tu", se inicialmente na interlocução, é neutro, tende a ser assimilado pelas duas outras posições. Isto é, no desenrolar da interlocução paranóica, o 'Tu' tende a se tornar um 'Eu' ou um Ele. Na paranóia, tende a desaparecer a instância do alocutário reconhecido na sua alteridade, uma elisão dessa posição no tropos discursivo. Quando o paranóico consegue afirmar seu discurso, no mínimo o seu interlocutor é colocado em uma posição passiva. Outras vezes, pode ocorrer mesmo a possibilidade de transformar o "Tu" em discípulo, em seguidor. Daí classicamente ser conhecida a desqualificação do outro na interlocução. Quando ocorre reação por parte do alocutor, encontramos a possibilidade da figura discursiva da querelância. Essa é uma das possibilidades perturbadoras no contacto com pacientes deste tipo. Pode sempre acontecer que o "Tu", inicialmente neutro, ou mesmo amado, venha a se tornar rapidamente um perseguidor e, por consequiência, em alguém de quem se fala, mas não alguém a quem se dirija a palavra efetivamente.

O colabamento do "Tu" instala uma grave dificuldade de comunicação. Emerge um sujeito pressuposto grandioso mas, ao mesmo tempo, muito solitário. Ou seja, o paranóico pode nada se queixar por ser muito narcísico, mas sempre tem a possibilidade de viver a maior das solidões pelo desaparecimento do pólo "Tu" de interlocução. Assinalar a solidão muitas vezes é um dos poucos caminhos que resta ao terapeuta para criar um vínculo que não desemboque em uma colusão do espaço comunicativo ou em uma oposição radical àquele que o escuta.

Entre o mundo inseguro do Sr. K. e o mundo cheio de perseguidores nomeados do delirante paranóico existem transições. Assim, no quadro 3, procuramos mostrar existir uma definição gradual dos referentes através do delírio, o que resolveria o clima de terror, insegurança e angústia do Sr. K., caso ele viesse a assumir as asserções e declarações delirantes como ocorre no caso do paciente apresentado na entrevista mais acima.

\section{Conclusão}

\section{A psicose é um distúrbio radical da personação}

O presente estudo privilegiou a investigação da referência dêitica na situação discursiva, especificamente com relação à categoria de pessoa. Esta dimensão encontra-se bastante perturbada, não somente no que diz respeito ao "Eu", mas também com relação às dimensões de não-Eu do triângulo dêitico. As dificuldades com relação à constituição da realidade efetiva dos referentes, representada nesse estudo principalmente pelo pronome "ele", pelo impessoal, se mostra intimamente articulada com a subjetivação do sujeito. Entendemos que o estudo da função dêitica da linguagem permitirá, em trabalhos futuros, uma melhor articulação com a problemática do $\mathrm{Eu}$, do ponto de vista psicanalítico, e com a comunicação lingüística, em especial dentro da família. Isto é, pensamos ter indicado, via estudo da dêixis discursiva e do processo de referenciação, existir a possibilidade de esclarecer alguns aspectos acerca da subjetivação e da intersubjetivação na psicose.

Quadro 3. As categorias dêiticas de pessoa no Sr. K e na Paranóia.

\begin{tabular}{|c|c|c|c|}
\hline Sr. K. & $\begin{array}{l}E u \\
? \\
\text { interpelado } \\
\text { constantemente, } \\
\text { sofrendo intrusões, } \\
\text { insecurizado. }\end{array}$ & $\begin{array}{l}\text { Tu } \\
? \\
\text { não confiável, } \\
\text { tende a se } \\
\text { torna ele. }\end{array}$ & $\begin{array}{l}\text { Ele } \\
? \\
\text { indefinido, em } \\
\text { transformação } \\
\text { constante. }\end{array}$ \\
\hline $\begin{array}{l}\text { Delírio de } \\
\text { perseguição }\end{array}$ & \begin{tabular}{|l}
$E u$ \\
Pressuposto \\
como grandioso, \\
narcísico.
\end{tabular} & $\begin{array}{l}\text { Tu } \\
\text { Tendência a } \\
\text { desaparecer } \\
\text { na } \\
\text { interlocução. }\end{array}$ & $\begin{array}{l}\text { Ele } \\
\text { Perseguidor. }\end{array}$ \\
\hline
\end{tabular}




\section{Referências}

Austin, J.L. (1990). Quando Dizer é Fazer - palavras e ação. Porto alegre: Artes Médicas (Originalmente publicado em 1962).

Benveniste, E. (1966). Problèmes de Linguistique Générale. Paris: Éditions Galimard.

Ducrot, O. \& Todorov, T. (1972). Dictionnaire Encyclopédique des Sciences du Langage. Paris: Éditions du Seuil.

Frege, G. (1978). Sobre o Sentido e a Referência. Lógica e Filosofia da Linguagem. São Paulo: Editora Cultrix/Edusp (Originalmente publicado em 1892).

Freud, S. (1976). Notas Psicanalíticas sobre um Relato Autobiográfico de um Caso de Paranóia - o Caso Schreber. Obras Psicológicas Completas de Sigmund Freud, vol. XII. Rio de Janeiro: Imago Editora (Originalmente publicado em 1911).
Freud, S. (1976). O estranho. Obras Psicológicas Completas de Sigmund Freud, vol. XVII. Rio de Janeiro: Imago Editora (Originalmente publicado em 1919).

Gagnepain, J. (1988). Du Vouloir Dire. Paris: Pergamon Press.

Jaspers, K. (1987). Psicopatologia Geral. São Paulo: Atheneu (Originalmente publicado em 1913).

Kafka, F. (1957). Le Procès. Paris: Éditions Gallimard (Originalmente publicado em 1926).

Parret, H. (1988). Enunciação e Pragmática. São Paulo: Unicamp.

Russell, B. (1966). An Inquiry into Meaning and Truth. London: George Allen \& Unwin Ltd.

Schotte, J. (1981-82, curso inédito). L'Analyse du Destin comme Patho-analyse. Louvain-la-Neuve: Université Catholique de Louvain. 